\title{
Nuevas tecnologías y traducción de textos sobre terrorismo global: el uso de AntConc para la gestión terminológica (alemán-español)
}

\author{
M. del Carmen Balbuena Torezano \& Alba Montes Sánchez \\ Universidad de Córdoba \\ mcbalbuena@uco.es \&132mosaa@uco.es \\ https://dx.doi.org.10.12795/futhark.2018.il3.0I
}

Fecha de recepción: 15.09.2018

Fecha de aceptación: 20.10.2018

Resumen: El presente estudio aborda el léxico y la terminología propias de un ámbito, el del terrorismo global, en alemán, con el objetivo fundamental de estudiarlo desde perspectivas contrastivas y aplicarlo a la traducción al español; por ello, teniendo en cuenta ambas lenguas de trabajo, hemos empleado textos pertenecientes a los ámbitos periodístico, político, legal, policial y religioso en lengua alemana para extraer términos y estudiar sus concordancias, colocaciones, y los agrupamientos posibles mediante el uso del software libre AntConc.

Palabras clave: terrorismo, traducción, terminología, seguridad ciudadana.

\section{New technologies and translation of texts on global terrorism: the use of AntConc for terminology management (German-Spanish)}

\begin{abstract}
This paper focuses on the language and terminology of global terrorism in German, in order to study it from contrastive perspectives and apply to the translation into Spanish. Therefore, considering these working languages, texts belonging to the press, political, legal, police and religious spheres in German language have been employed in order to extract terms and study their possible concordances, positions, and word clusters using the free software AntConc.
\end{abstract}

Key words: translation, terrorism, terminology, public safety.

Sumario: I. Estado de la cuestión y planteamiento del estudio. 2. Definición de terrorismo. 2.I. Terrorismo politico. 2.2. Terrorismo económico. 2.3. Terrorismo de Estado. 2.4. Terrorismo nacionalista. 2.5. Ecoterrorismo. 
2.6. Terrorismo ambiental. 2.7. Terrorismo doméstico. 2.8. Terrorismo religioso. 2.9. Terrorismo nuclear. 2.10. Ciberterrorismo. 2.II. Terrorismo internacional. 3. La Resolución UN 2178 (2014) y su aplicación en España y Alemania. 3.I. La aplicación de la Resolución UN 2178 (2014) en España. 3.2. La aplicación de la Resolución Un 2178 (2014) en Alemania. 4. Corpus textual. 5. Análisis con AntConc. 6. Resultados. Conclusiones.

\section{Estado de la cuestión y planteamiento del estudio}

Los grandes atentados terroristas del II de septiembre de $200 \mathrm{I}$ en Estados Unidos y el II de marzo de 2004 en Madrid, así como el 7 de julio de 2005 en Londres obligaron a los Estados democráticos occidentales a adoptar medidas legislativas contra el fenómeno terrorista para endurecer las penas aplicadas a este tipo de delitos. Por primera vez los gobiernos contemplan el terrorismo como un fenómeno global y complejo, desde múltiples perspectivas: cultural, política, religiosa, antropológica... en consecuencia, los fenómenos de inmigración y los movimientos migratorios, el asilo y el problema de los refugiados han sufrido igualmente variaciones jurídicas, con las consiguientes reformas restrictivas en la legislación de extranjería e inmigración. Este nuevo escenario ha determinado, en materia investigadora, una corriente poliédrica para intentar abordar, en su conjunto, los estudios sobre inmigración, refugiados, terrorismo, y seguridad en el ámbito de la Unión Europea. Consecuentemente, el autodenominado Estado Islámico o DAESH es uno de los puntos que encabeza las agendas políticas europeas.

Así, son numerosos los ámbitos desde los cuales se ha abordado el estudio de este problema global: trabajos sobre el concepto de terrorismo global y yihadismo (Cañete 2017; Jordán 2009; Kaldor 2003; Lobato 2017; Powell 2013); sobre el régimen jurídico aplicable a esta amenaza transnacional (Álvarez y González 2006; Barrenechea, 2007; Demurtas 20I4; Núñez 2016); sobre seguridad, ciberseguridad y el uso de internet con fines terroristas (Álvarez y Perdomo 2017; Herráiz y Soiza 2017); sobre la protección de los derechos humanos (Consejo Internacional para el Estudio de los Derechos Humanos 2008); sobre la relación entre terrorismo, refugiados e integración (Cantón 2017; Del Valle 2016; Goig 2016; González 20I5); se ha tratado igualmente el tema desde el punto de vista del discurso periodístico, el lenguaje y la comunicación (Apter 2009; Bielsa 2009; Elorza 2009; García Abadillo 2016; Lluis 2016; Bañón 2017; Ramírez 2017); los estudios relacionados con la terminología, la traducción o la lingüística aplicada son, sin embargo, escasos en este ámbito (Carrión 20I4; Pegenaute 20I2). En este sentido, a la ciudadanía no le son extraños términos como "imán", "célula", "radicalización", “islamofobia”, “yihadismo”, "talibán” o “fundamentalismo”, principalmente por su aparición en los medios informativos; sin embargo, desconocen expresiones como "terrorismo hermenéutico", “foreign fighter”, "guerra híbrida”, "ideología takfir", 
"fatua" o "doctrina Gerasinov". Parte fundamental de este discurso del terror, y de la islamofobia y el rechazo que genera en la población la comunidad musulmana a consecuencia de los ataques sufridos en Europa son las figuras retóricas y las metáforas empleadas por terroristas e islamófobos, tales como "construcción estatal", "enemigo cercano", "enemigo lejano" o "cruzada contra el Estado Islámico". Consideramos que la búsqueda de esta terminología, así como las expresiones que derivan de este tipo de discursos, y su equivalencia en las lenguas europeas de los países actualmente considerados "objetivos" para llevar a cabo la yihad, resulta una herramienta necesaria para ayudar a prevenir y perseguir el terrorismo global y la islamofobia, al tiempo que proteger y preparar a la ciudadanía contra ambos fenómenos violentos. Para hacer frente a la amenaza terrorista, por tanto, es primordial la cooperación y colaboración entre los Estados, lo cual requiere de un profesional de la Traducción e Interpretación para llevarlo a cabo. Para combatir la amenaza terrorista es primordial la cooperación y colaboración entre los Estados miembro, lo cual requiere de un profesional de la Traducción e Interpretación para llevarlo a cabo.

Para el estudio que pretendemos llevar a cabo partimos de la siguiente hipótesis de partida: el conocimiento de las relaciones conceptuales y la terminología propia de entornos terroristas, y su equivalencia a otras lenguas europeas permitirá, mediante la traducción, contribuir a la lucha antiterrorista en el marco del terrorismo global, en cualquiera de sus modalidades. La creación de glosarios resultantes de la búsqueda terminológica y el establecimiento de equivalencias constituirán una útil herramienta para traductores e intérpretes que deban desempeñar su ejercicio profesional en este sector.

El trabajo que presentamos aquí tiene como finalidad última producir un recurso bilingüe (alemán-español) que reproduzca la estructura conceptual y su variación terminológica en el dominio especializado del terrorismo internacional, desde cualquiera de los ámbitos reseñados, contribuyendo con ello a la difusión del conocimiento en torno a esta compleja y poliédrica cuestión. Son objetivos generales de este estudio:

I. Desarrollo de la comunicación especializada y no especializada en torno al terrorismo global en las lenguas de trabajo, esto es, el español y el alemán.

2. Estudio del léxico del ámbito de la violencia terrorista internacional desde perspectivas contrastivas.

Junto a estos objetivos generales, perseguimos también la consecución de otros objetivos específicos: 
I. Creación de un corpus de textos relacionados con la temática del terrorismo global en inglés y alemán, especialmente en los ámbitos periodístico, político, legal, policial y religioso.

2. Elaboración de un inventario de relaciones conceptuales específicas del evento [TERRORISMO] mediante el uso de AntConc.

3. Creación de una base de datos terminológica en la que los conceptos estén vinculados a una ontología, que será el vínculo entre las dos lenguas de trabajo.

Para llevar a cabo el estudio aquí planteado, hemos dividido el trabajo en dos partes bien diferenciadas. Por un lado, abordamos el concepto de "terrorismo", así como las variedades y tipología de actuaciones terroristas existentes en la actualidad, y la Resolución de Naciones Unidas relativa a la lucha anti-terrorista y su aplicación en España y Alemania. Una vez establecidos estos presupuestos de tipo teórico, llevamos a cabo una selección de textos representativos que conforman el corpus textual al que aplicaremos el análisis con AntConc. Determinaremos los resultados obtenidos, y a partir de ellos, las correspondientes conclusiones.

\section{Definición de terrorismo}

No existe una definición unívoca del término "terrorismo", pues ciertamente presenta muchas particularidades para tener una única definición. Originado en Francia en los años de período revolucionario (I789-1799) como terrorisme', el vocablo se obtuvo de la unión del término latino terreur, "sentir un miedo intenso o terror", y el sufijo -isme, "doctrina", "creencia" o "corriente de pensamiento"; por tanto, era posible definirlo como "simpatía con la idea de que a través de actos de violencia, sembrando el terror, se pueden lograr ciertos propósitos". Por otra parte, hay autores como Schmidt y Jongman (1988) que proponen hasta 109 definiciones de término "terrorismo"; sin embargo, aún quedan ciertos aspectos por resolver que dan lugar a confusión:

a) la línea divisoria entre terrorismo y otras formas de violencia política;

b) la diferenciación entre terrorismo y otros delitos ordinarios; $y$

c) la relación entre terrorismo y la guerra de guerrillas.

Como afirma Wilkinson (1974: 17), determinados actos terroristas podrían dar pie a confusión con delitos ordinarios, como por ejemplo el asesinato, los

' En línea: http://www.cnrtl.frl. [Fecha de consulta: 03.02.18]. 
daños y el crimen de guerra que, aunque actúan como actos de terror, su finalidad no es propagar miedos sociales extensos, únicamente méritos puntuales. En este sentido, afirma el $\mathrm{FBI}^{2}$ :

The FBI investigates terrorism-related matters without regard to race, religion, national origin, or gender. Reference to individual members of any political, ethnic, or religious group in this report is not meant to imply that all members of that group are terrorists. Terrorists represent a small criminal minority in any larger social context.

Teniendo en cuenta lo expuesto anteriormente, una definición de terrorismo podría ser la que propone Calduch (1993: 327):

Una estrategia de relación política basada en el uso de la violencia y de las amenazas de violencia por un grupo organizado, con objeto de inducir un sentimiento de terror o inseguridad extrema en una colectividad humana no beligerante y facilitar así el logro de sus demandas.

Sin embargo, si deseamos ser más precisos en la definición de este complejo término, hemos de tener en cuenta distintas perspectivas:

a) Definición gramatical ${ }^{3}$ :

I. m. Dominación por el terror. 2. m. Sucesión de actos de violencia ejecutados para infundir terror. 3. $\mathrm{m}$. Actuación criminal de bandas organizadas, que, reiteradamente y por lo común de modo indiscriminado, pretende crear alarma social con fines políticos.

b) Definición académica (Brieguer 20II: 40):

Terrorismo es, en la mayoría de los casos, esencialmente, un acto político. Tiene como propósito causar daños dramáticos y mortales sobre civiles y crear una atmósfera de miedo, generalmente por un motivo político o ideológico; sea este secular o religioso [...] El terrorismo es y busca un asalto sobre los principios de la ley, el orden, los derechos humanos y la resolución pacífica de disputas sobre las cuales se creó este organismo mundial [...] El terrorismo no es un fenómeno unívoco, sino que debe ser entendido a la luz del contexto en el cual las actividades terroristas aparecen [...] El terror ha

\footnotetext{
2 "EI FBI investiga casos relacionados con el terrorismo sin atender a raza, religión, nación de origen o género. Las referencias a individuos miembros de cualquier grupo político, étnico o religioso en este informe no implican que todos los miembros de dicho grupo sean terroristas. Los terroristas representan una escasa minoría criminal en cualquier contexto social amplio". Traducción propia. Fuente: https://www.fbi.gov/stats-services/publications/terrorism-2002-2005. [Fecha de consulta: 15.02.2018].

${ }^{3}$ Diccionario de la Lengua Española, RAE. En línea: https://dle.rae.es/?id=Zd3L6Oc. [Fecha de consulta: 15.02.2018].

Futhark I3 (2018) 
sido usado como táctica en casi todos los rincones del planeta, sin distinguir riqueza, género o edad de sus víctimas, que son en su mayoría civiles.

c) Definición jurídica (Osorio, 2006: 939):

Actos de violencia en contra de personas, la libertad, la propiedad, la seguridad común, la tranquilidad pública, los poderes públicos y el orden constitucional o contra la Administración Pública.

d) Definición política (de la Corte, 2009):

El terrorismo es considerado una forma de opresión de carácter tanto social como político, llevado a cabo por medio de acciones puntuales de carácter violento hacia la población civil y cuyos resultados atentan ante cualquier derecho humano.

\section{e) Definición psicológica ${ }^{4}$ :}

El terrorismo es la imitación y aplicación de los métodos del terror por los (al menos, en principio) débiles, los despreciados, los desesperados, que ven en el terrorismo el único medio de conseguir que se les tome en serio y se les escuche. [...] El terrorismo contemporáneo presenta tres especificidades: el objetivo de la acción es escogido en base a su valor simbólico; la acción se propone efectos psicológicos más que materiales, y se articulan mensajes diferentes para objetivos diferentes. No cabe duda de que el terror es, en gran parte un hecho expresivo, donde el observador puede constatar que el acto violento implica un significado más amplio que sus partes integrantes. Precisamente, la relativa eficacia del terrorismo deriva de esa naturaleza alegórica: mostrando la debilidad de la estructura social, los insurgentes demuestran, no solo su propia fuerza y la debilidad de los gobernantes, sino también la impotencia de la sociedad para apoyar a sus miembros en circunstancias tan críticas.

\section{f) Definición criminológica (Bueno, 2009: 62):}

[...] más afortunada ha sido la doctrina en pergeñar un concepto criminológico del terrorismo sobre la base de la conjunción de estos tres elementos: violencia encaminada a producir terror, con una finalidad política (aceptado por el Convenio de Ginebra para la prevención y represión del terrorismo de 16 de noviembre de 1937). Y sin embargo tampoco en este reducido ámbito se puede cantar victoria, porque la definición indicada puede convenir al llamado terrorismo revolucionario, e incluso al terrorismo de Estado, pero no al más reciente terrorismo fundamentalista basado en razones religiosas.

\section{g) Definición Naciones Unidas ${ }^{5}$ :}

${ }^{4}$ Definición del psiquiatra vienés Friedrich Hacker (González 2006: 17s.).

${ }^{5}$ En línea: https://www.ohchr.org/Documents/Publications/Factsheet32sp.pdf [Fecha de consulta: $10.02 .2018]$ 
Cualquier acto destinado a causar la muerte o lesiones a un civil $\circ$ un no combatiente cuando el propósito de dicho acto sea intimidar a una población u obligar a un gobierno o a una organización internacional a realizar un acto o abstenerse de hacerlo.

Por tanto, a tenor de las distintas definiciones que acabamos de ver es posible concluir que hay tantas definiciones de terrorismo como tipos de terrorismo existentes. Por ello, a continuación, vamos a hacer un breve repaso por los distintos tipos de terrorismo que hay en la actualidad, contemplados todos ellos desde distintas perspectivas.

\section{I. Terrorismo político}

El terrorismo político es, según Wardlaw (1986: 57)

(...) el uso, o la amenaza de uso, de la violencia por parte de un individuo o grupo, lo mismo si actúa a favor o contra la establecida, cuando esa acción pretende crear una angustia extrema o efectos inductores de miedo sobre un grupo seleccionado y mayor que el de las víctimas inmediatas, con el propósito de obligar a este grupo a que acceda a las demandas políticas de los perpetradores.

\subsection{Terrorismo económico}

El Geneva Centre for Security Policy (GCSC) establece la siguiente definición de terrorismo económico, distinguiéndolo claramente de la denominada "guerra económica":

A diferencia de la guerra económica, el terrorismo económico es llevado a cabo por actores internacionales no estatales. Puede englobar acciones coordinadas y sofisticadas o acciones desestabilizadoras masivas con el fin de irrumpir en la estabilidad económica de un estado, un grupo de estados o una sociedad por motivos ideológicos o religiosos. Estas acciones, si son emprendidas, pueden ser violentas o no. Pueden tener efectos inmediatos o conllevar efectos psicológicos que a su vez tienen consecuencias económicas ${ }^{6}$.

\subsection{Terrorismo de Estado}

J. Giraldo define el terrorismo de Estado del siguiente modo:

El Terrorismo de Estado se da cuando el Estado mismo se convierte en agente de terror, ya sea porque conduce un conflicto, guerra o conmoción interna sin ceñirse a las normas del "Derecho en la Guerra", ya sea porque a través de sus estructuras, instituciones, procedimientos o prácticas, coloca bajo amenaza los valores fundamentales: vida, integridad o libertad de sus ciudadanos, creando campos ambiguos donde la seguridad o el riesgo están sometidos a la

${ }^{6}$ En línea: http://www.gcsp.ch/. [Fecha e consulta: 15.02.2018]. 
arbitrariedad, o señalando campos de riesgo no ambiguos pero inspirándose en principios irracionales o anti-éticos ${ }^{7}$.

\subsection{Terrorismo nacionalista}

No hemos de confundir el terrorismo de Estado, en el que es el propio Estado el que causa el terror, con el terrorismo nacionalista, cuyo fin es distinto. A este respecto, $\mathrm{H}$. Hyunwook define el terrorismo nacionalista como ${ }^{8}$ :

Nationalist terrorists seek to form a separate state for their own national group, often by drawing attention to a fight for "national liberation" that they think the world has ignored. Nationalist terrorism can be difficult to define, since many groups accused of the practice insist that they are not terrorists but freedom fighters.

\subsection{Ecoterrorismo}

Cuando el terrorismo tiene lugar porque se desea apoyar una causa medioambiental o relacionada con la ecología recibe el nombre de “ecoterrorismo". En este sentido, E. Chalecki (200l: 4) afirma:

Eco-terrorism is the violent destruction of property perpetrated by the radical fringes of environmental groups in the name of saving the environment from further human encroachment and destruction?.

\subsection{Terrorismo ambiental}

Del mismo modo, podemos definir el terrorismo ambiental (Chalecki 200I: 4) como "(...) the unlawful use of force against in situ environmental resources so as to deprive populations of their benefit(s) and/or destroy other property"10.

\subsection{Terrorismo doméstico}

\footnotetext{
${ }^{7}$ En línea: http://www.javiergiraldo.org/es. [Fecha de consulta: I5.02.20I8].

8 “Los terroristas nacionalistas pretenden formar un estado independiente para su propio grupo nacional, a menudo enfatizando en una lucha por la libertad nacional que creen que el mundo ha ignorado. Resulta difícil de definir el terrorismo nacional, puesto que un gran número de grupos acusados por esta práctica insisten en que no son terroristas, sino que luchan por la libertad". Traducción propia. Fuente: http://www.terrorismanswers.com/terrorism/types.html. [Fecha de consulta: 15.02.2018].

9 "El eco-terrorismo es la destrucción violenta de la propiedad perpetradas por grupos violentos de ecologistas para proteger al medioambiente del daño y la destrucción ocasionados por el hombre". Traducción propia.

10 “(...) el uso ilegal de la fuerza contra recursos ambientales in situ con el fin de despojar a las poblaciones de sus beneficios y/o en la destrucción de propiedades ajenas”. Traducción propia.
} 
Resulta cuanto menos curioso que exista el concepto de "terrorismo doméstico", entendido como el terrorismo dentro del propio país, y contra la población de dicho país. El concepto de terrorismo doméstico se emplea, sobre todo en Estados Unidos:

Domestic terrorism is the unlawful use, or threatened use, of violence by a group or individual operating entirely within the United States (or its territories), committed against persons or property to intimidate or coerce a government, the civilian population, or any segment thereof, in furtherance of political or social objectives"l.

\subsection{Terrorismo religioso}

El terrorismo religioso, a menudo resultado de un fanatismo difícil de erradicar, se concibe como

Religious terrorists seek to use violence to further what they see as divinely commanded purposes, often targeting broad categories of foes in an attempt to bring about sweeping changes. Religious terrorism is characterized by compliance with belief. As Hoffman puts it, religious terrorists can use limitless violence against an open-ended category of targets, that is, anyone who is not a member of the terrorist's religion or religious sect 12 .

\subsection{Terrorismo nuclear}

El terrorismo nuclear, según Martín (2007: 19), es una forma de terrorismo que viene determinada por el tipo de ataque, siendo lo habitual “(...) el uso de armas nucleares o radiológicas, o el ataque a instalaciones nucleares, con el fin de infundir terror en la población"'13.

\subsection{Ciberterrorismo}

En la era de la globalización, en la que las comunicaciones se efectúan a través de la Web, una modalidad de terrorismo muy desarrollada es la que se crea

'I. "El terrorismo doméstico es el uso ilícito o amenazador de la violencia cometido contra personas o propiedades con el fin de intimidar o coaccionar a un gobierno, a la población civil o a cualquiera de los mismos. Lo realizan grupos o individuos que operan completamente en los Estados Unidos (o en cualquiera sus territorios) para lograr sus objetivos políticos y sociales". Traducción propia. Fuente: https://www.fbi.gov/stats-services/publications/terrorism-2002-2005. [Fecha de consulta: 18.02.2018].

12 "Los terroristas religiosos hacen uso de la violencia para promover lo que ven como causa de mandato divino, a menudo dirigido a diversos oponentes con el fin de lograr un cambio generalizado. El terrorismo religioso se caracteriza por el cumplimiento de una creencia Como afirma Hoffman, los terroristas religiosos pueden usar la violencia de forma ilimitada contra una gran cantidad de objetivos, es decir, contra cualquiera que no pertenezca a su religión o secta religiosa". Traducción propia. http://www.terrorismanswers.com/terrorism/types.html. [Fecha de consulta: 18.02.20I8]. 
y se desarrolla tomando como "espacio" y arma la Web y el ordenador. Así podemos hablar de "ciberterrorismo", y definirlo como:

It is defined as the use of computing resources to intimidate or coerce others. An example of cyber-terrorism could be hacking into a hospital computer system and changing someone's medicine prescription to a lethal dosage as an act of revenge ${ }^{14}$.

\section{I I. Terrorismo internacional}

Afirma Calduch (1993: 343ss.) que el terrorismo internacional es

Aquella forma de terrorismo que de un modo directo se desarrolla en o afecta a diversos países, sus ciudadanos y/o territorios, o a los representantes de organizaciones intergubernamentales.

Por su parte, Khader (2010: 315) especifica algo más en su definición, haciendo especial referencia al terrorismo de carácter islámico, cuando habla de terrorismo internacional:

El nuevo terrorismo está directamente vinculado con la occidentalización de los extremistas y terroristas lo que significa, como dice Marc Ferro, que la radicalización islámica y el terrorismo se han desplazado hacia los márgenes del mundo musulmán, tanto a nivel geográfico como sociológico. En realidad, lo que caracteriza a muchos hombres de la reciente generación de Al Qaeda (sobre todo después de 1992), no es solo el hecho de que son instruidos y más bien de clase media, sino también, y sobre todo, que han roto con el mundo musulmán. Pero esa ruptura es vivida como una traición, ya que abandonar su país de origen, en la infancia o posteriormente, engendra en el candidato a terrorista un sentimiento de haberse sustraído indebidamente a la desgracia de sus correligionarios que viven en las sociedades musulmanas, percibidas como humilladas (en Bosnia, Irak, Palestina, etc.).

\section{La Resolución UN 2178 (2014)}

El 24 de septiembre de 2014 el Consejo de Seguridad de las Naciones Unidas adopta, por unanimidad la Resolución 2178 relativa a las Amenazas a la Paz y la Seguridad Internacional, que han sido causadas por actos terroristas. La propia ONU ${ }^{15}$ reconoció que la aprobación de la Resolución 2178 (2014) del Consejo de

\footnotetext{
14 "Se define como el uso de recursos informáticos para intimidar o coaccionar a otros ciudadanos. Un ejemplo de ciberterrorismo podría ser piratear el sistema informático de un hospital y modificar una receta médica de forma letal con ánimo de venganza”. Traducción propia. Fuente: http://www.ict.org/inter-ter/frame.html. [Fecha de consulta: 18.02.2018].

15 Vid. https://www.un.org/counterterrorism/ctitf/es/foreign-terrorist-fighters. [Fecha de consulta: 10.02.2018].
} 
Seguridad priorizó la cuestión de los combatientes terroristas extranjeros en la agenda internacional. Aprobada bajo el Capítulo VII de la Carta de las Naciones Unidas, la Resolución 2178 tiene por meta que la Comunidad Internacional persista en el refuerzo de la lucha contra el terrorismo, ampliando las prevenciones de Resoluciones precedentes como la 1373 (200I), por la que se creó el Comité Contra el Terrorismo (CTC) ${ }^{16}$ de Naciones Unidas, y la 1267 (1999), por la que se establecieron medidas contra la organización terrorista Al Qaeda. Esto implica que la Resolución es jurídicamente vinculante para los 193 Estados miembros.

Para lograr ese objetivo, la Resolución 2178 solicita a los Estados miembros de la Comunidad Internacional la adopción de disposiciones que sancionen el reclutamiento y los viajes de los combatientes terroristas extranjeros (CTE), y la ampliación de su cooperación para enfrentar esta amenaza, de forma que cuando sea conveniente se constituyan acuerdos internacionales y medidas para colaborar con indagaciones sobre listas de sospechosos e investigaciones o procesamientos penales. Igualmente insta a los Estados miembros a exigir a las compañías aéreas que sobrevuelen sus territorios a presentar a las autoridades nacionales de forma anticipada datos sobre los pasajeros con el fin de paralizar la entrada o tránsito de aquellos que figuren en las listas de sospechosos. Del mismo modo, se incide en que es necesario dedicar especial atención a la amenaza tecnológica que supone la unión de CTE al Estado Islámico, el Frente Al -Nusra y todos los grupos, empresas y entidades asociados con Al-Qaeda y alienta a los Estados miembros a la puesta en marcha de estrategias internas y cooperación internacional para contrarrestar el extremismo violento.

Finalmente, en esta Resolución el Consejo de Seguridad de la ONU destaca el trabajo realizado por el Foro Mundial contra el Terrorismo, en particular la aprobación de un amplio conjunto de buenas prácticas, y los esfuerzos efectuados por INTERPOL con el objeto de encarar la amenaza que plantean los CTE.

Todo ello en un marco de colaboración internacional, en el que se contempla la obligación de los Estados de que todas las medidas que favorezcan a lucha antiterrorista respeten el derecho internacional de los derechos humanos, el derecho internacional de los refugiados y el derecho internacional humanitario, reiterando que el respeto de las libertades fundamentales, el estado de derecho y los derechos humanos son complementarios y recíprocos, vitales para un combate eficaz contra el terrorismo.

3.I. La aplicación de la Resolución UN 2178 (20I4) en España

\footnotetext{
${ }^{16}$ Siglas en inglés (The Counter-Terrorism Committee). Vid.: https://www.un.org/sc/ctc/about-us/ [Fecha de consulta: 20.02.2018].
} 
El 18 de septiembre de 2015, la Unión Europea adoptó la Decisión (UE) 2015/1914 del Consejo relativa a la firma, en nombre de la Unión Europea, del referido Protocolo adicional del Convenio del Consejo de Europa para prevenir la amenaza terrorista. De acuerdo con el Considerando número 3 de la Decisión adoptada por el Consejo de Seguridad de la Unión Europea:

Una comprensión común de los delitos relacionados con los combatientes terroristas extranjeros y los delitos de naturaleza preparatoria que tengan el potencial de conducir a la comisión de delitos de terrorismo, contribuiría a aumentar la eficacia de los instrumentos de la justicia penal y la cooperación a nivel internacional y de la Unión.

La Ley Orgánica $2 / 2015$, de 30 de marzo, por la que se modifica la Ley Orgánica 10/1995, de 23 de noviembre del Código Penal en materia de delitos de terrorismo, entró en vigor en nuestro país, como pone de relieve en su propio Preámbulo, ante la fundada preocupación internacional por el crecimiento y recrudecimiento de la actividad terrorista. La Resolución del Consejo de Seguridad de Naciones Unidas 2178, aprobada el 24 de septiembre de 2014 es la precursora de esta Ley Orgánica modificadora de nuestro Código Penal, y esta resolución no sólo se limita a denunciar en un marco político-internacional los actos de terrorismo, sino que muestra una honda preocupación por las nuevas formas en las que operan estas organizaciones terroristas, no sólo en cuanto a sus actos de desequilibrio de la paz social, sino también en cuanto al modus operandi en lo que a captación, difusión y adiestramiento de nuevos adeptos respecta. La Resolución del Consejo de Seguridad de la ONU la impone la obligación a los Estados miembros de incluir estas consideraciones en sus Ordenamientos Jurídicos para permitir en todos ellos la perseguibilidad y punibilidad de las conductas terroristas descritas en la misma resolución.

En 2015, con la entrada en vigor de la Ley Orgánica $2 / 2015$ de 30 de marzo se ha modificado todo el Capítulo VII, del Título XXII, del Libro II, el cual comprende desde el artículo 57/ hasta el 580 de nuestro Código Penal. Comienza ahora este Capítulo VII (en su artículo 57I) señalando lo que sería organización terrorista a efectos penales, y lo hace valiéndose de la definición que se da de grupo criminal en los artículos 570 bis y 570 ter del mismo cuerpo legal, pero, añade el 57l del Código Penal que para ser considerados organización terrorista, deben tener por finalidad la comisión de delitos tipificados en la sección II del Capítulo VII, objeto de nuestro estudio. Es importante esta señalización porque antes de la reforma que introdujo la Ley Orgánica 2/2015, este artículo 57l del Código Penal establecía una especial intencionalidad a la hora considerar a una organización terrorista como tal en tanto en cuanto el artículo terminaba con las siguientes palabras "tengan por finalidad o por objeto subvertir el orden constitucional o alterar gravemente la paz pública mediante la perpetración de 
cualquiera de los delitos previstos en la Sección siguiente”. Es decir, según el Código, debía existir esa finalidad de la organización de subvertir el orden constitucional o alterar gravemente la paz para poder considerarla terrorista. Ahora esa apostilla de intencionalidad se incluye en la definición de delito de terrorismo del artículo 573 y por tanto la definición que se da de organización terrorista es más amplia y abarca más porque se limita a especificar que deben ser organizaciones conforme al $\mathbf{5 7 0}$ bis y $\mathbf{5 7 0}$ ter que cometan delitos comprendidos en la Sección II del Capítulo VII relativo a las organizaciones terroristas, moviendo esa apostilla de específica intencionalidad en la descripción del delito de terrorismo. El hecho de este movimiento de un artículo a otro de la intención de subvertir el orden constitucional o alterar gravemente la paz social cobra especial sentido en tanto en cuanto sería muy complicado poder determinar la intención de una organización que se acaba de crear cuando aún no ha cometido ningún hecho, sea o no delictivo; sin embargo, incluyendo la intencionalidad en la descripción de los delitos de terrorismo, sería mucho más fácil determinar la intención del que comete el hecho en base a cómo lo comete.

Siguiendo nuestro estudio, el artículo 573 bis del Código penal viene a traernos el listado de las penas para los delitos de terrorismo que el artículo 573 del mismo cuerpo legal nos enumera, y aquí se encuentra la que consideramos la modificación más importante en cuanto a diferencia existente entre el Código Penal de antes de la Ley Orgánica 2/20I5 de 30 de marzo y el Código Penal actual, y es la inclusión de la pena máxima contemplada en nuestro ordenamiento Jurídico; estamos hablando, por supuesto, de la prisión permanente revisable para los delitos de terrorismo que recoge el artículo 573 del Código Penal si se en la comisión de cualquiera de ellos se causara la muerte de una persona. Se trata pues, de un endurecimiento de las penas de terrorismo cuando se cause la muerte de alguien porque antes de la reforma del Código Penal la pena prevista para estos casos era de entre 20 y 30 años. Este endurecimiento de la pena responde a la honda preocupación existente en la comunidad internacional y que busca, combatir la proliferación de actos terroristas que hemos sufrido estos últimos años.

Otra novedad, y bastante acertada en nuestra opinión, sobre todo para poner freno a los delitos cometidos por los llamados "lobos solitarios", es el castigo por medio del artículo 575 del Código Penal no ya a aquellos que se dediquen a captar a otros con el fin de que se unan a las organizaciones terroristas, sino a los actos de adoctrinamiento, adiestramiento militar, de combate, aprendizaje de técnicas de desarrollo de armas químicas o biológicas, $\circ$ la elaboración de explosivos por medio de un tercero o por sí mismo con la finalidad de llevar a cabo actos tipificados como delitos de terrorismo; es decir, se castiga también a aquel que recibe conscientemente adoctrinamiento. Además, se tipifica en el punto 3 de este artículo, a aquel que se traslade o establezca en un territorio 
extranjero controlado por un grupo terrorista con la intención de recibir adoctrinamiento, entrenamiento de combate o captación.

La reforma que se ha dado de este Capítulo referente al terrorismo ha incluido también los delitos que ya estaban tipificados antes de la reforma operada por la Ley orgánica $2 / 2015$, de 30 de marzo y además los ha dotado de más contenido especificando en ellos diferentes circunstancias para así ajustar las penas a la gravedad del delito cometido. Claro ejemplo de ello es el delito de enaltecimiento al terrorismo contenido, en el artículo 578 del Código Penal, el cual ha pasado de castigarse de uno a dos años a de uno a tres años, y aparte, se incluyen en la redacción de este artículo diferentes supuestos de comisión con indicación de la pena correspondiente.

\subsection{La aplicación de la Resolución UN 2 I 78 (20I4) en Alemania}

El 20 de octubre de 2014, el entonces Ministro Federal de Justicia y Protección al Consumidor alemán, Heiko Maas, informó sobre una renovación en las medidas para combatir el terrorismo propagado por ISIS. De acuerdo con el Ministro, la resolución de la ONU 2178 (2014) supone un gran impacto en la Ley de Inmigración y la Ley de Pasaportes en Alemania.

En la elaboración de la modificación legal se especifican los siguientes objetivos, acorde con la Resolución dictada por la ONU:

- La implementación de controles fronterizos efectivos;

- Controles más estrictos sobre la emisión de documentos de identidad y de viaje,

- Una evaluación de riesgos y control de viajeros a través de un procedimiento basado en la evidencia;

- Prevención del cruce fronterizo de CTE, y

- Obstaculizaciones en la entrada y tránsito de cualquier persona que financie, planee, prepare o lleve a cabo actividades terroristas.

La Ley de Pasaportes vigente en Alemania ha sido enmendada y acoge diversas medidas que afectan a los ciudadanos alemanes. En primer lugar, se impide la salida del país germano si las autoridades consideran que el sospechoso corre riesgo de unirse a grupos terroristas o ser partícipe de graves actos de violencia terrorista $y$, en consecuencia, será considerado penalmente responsable. Esta acción pondría en riesgo la seguridad interna y externa y otros intereses sustanciales de la República Federal Alemana, como por ejemplo la reputación internacional. 
Con esta modificación legal no solo se otorga un mayor poder a los controles fronterizos, operarios de aduanas y fuerzas del gobierno, sino también al servicio militar; es decir, también se condena quien abandonase el servicio militar estando fuera de Alemania para alistarse en las filas del autodenominado Estado Islámico.

En segundo lugar, se tipifica un delito de financiación de cualquier clase en beneficio de grupos y/u organizaciones terroristas, como es el caso del El. De hecho, Alemania ya cuenta con una estricta ley antiterrorista en la cual se atribuyen consecuencias penales a toda aquella persona que apoye el terrorismo del El en Siria e Irak, siendo punibles las campañas de propaganda en apoyo a estas organizaciones.

Con respecto a la residencia, se recogen medidas que restringen la entrada y salida de extranjeros. Se otorgan diferentes permisos de residencia, acogidos tras los atentados de 200I, según corresponda con residencia temporal o permanente, incluso hay algunos países que están exentos de solicitar este permiso. Sin embargo, se prohíbe otorgar permisos de residencia a terroristas o extranjeros con riesgo de pertenencia, apoyo o participación en un grupo armado.

Por supuesto, se atiende a los numerosos tratados y acuerdos para combatir el terrorismo internacional, por lo que se deben cumplir con cautela las normas establecidas por la comunidad internacional y europea. El problema surge con el Código de fronteras Schengen, ya que en Europa se han suprimido multitud de controles fronterizos para acomodar la comunidad a los ciudadanos. Los ciudadanos de la Unión Europea gozan de total movimiento entre diferentes países pertenecientes, franqueándose las fronteras entre las diferentes naciones. La Resolución 2178 (2014) exige mayor precaución en los controles fronterizos, lo que Alemania reforzará, pero el Espacio Schengen es una cuestión de Derecho Europeo que se debe enmendar, no una cuestión nacional.

Tomando como precedente lo anteriormente explicado, a finales de septiembre de 2014 Alemania consideró reforzar la seguridad de los controles fronterizos, especialmente para viajeros sospechosos de pertenecer a grupos armados. Para ello, se implementó una marca determinada en los documentos de identidad de los mencionados "sospechosos" con el fin de controlar su localización en Alemania y alertar a demás funcionarios fronterizos de otros países europeos. Por último, el gobierno alemán plante retirar la nacionalidad alemana a los presuntos militantes islamistas y reforzar la seguridad fronteriza para aquellos combatientes que pretenden regresar al país germano. 


\section{Corpus textual}

Existe una estrecha relación entre la traducción y el terrorismo $y$, sin ninguna duda, su vinculación es muy relevante tanto para las fuerzas de seguridad como para la ciudadanía. A nivel mundial, y recientemente en Europa, las medidas antiterroristas han sido las principales protagonistas en las agendas de los líderes políticos, aumentando el nivel de alerta de países europeos debido a la inminente amenaza. Consecuentemente, los puestos laborales de traductores e intérpretes han proliferado en todo el continente. Es esencial el análisis, la consulta, comprobación y verificación de la información que reciben los agentes de seguridad, la cual normalmente se transmite en árabe. Además de ello, se requiere una gran labor de los traductores e intérpretes en redes sociales y en interrogatorios e intervenciones policíacas. Un caso al que normalmente se enfrenta el traductor es a organizaciones como el DAESH que cada vez amplían más sus propagandas terroristas en Europa con el fin de captar nuevos miembros.

Por tanto, el traductor-intérprete, además de traducir documentos jurídicos oficiales en la Unión Europea, interpretar conversaciones telefónicas del árabe a cualquier idioma occidental o traducir material propagandístico para captar nuevos terroristas, también ejerce el rol de agente de intervención social en contextos geopolíticos, ya que las fronteras culturales y lingüísticas son, en muchas ocasiones, causa de conflictos bélicos.

Para la creación del corpus textual objeto de estudio, hemos compilado un total de 10 textos en lengua alemana en materia de terrorismo, centrándonos en el terrorismo yihadista $y$, especialmente en los combatientes terroristas extranjeros, en los siguientes ámbitos:

—Ámbito periodístico

- Texto I: Die Weltkarte des Terrors

- Texto 2: Terrorismus: I4I Personen mit Gefährderpotenzial in Österreich

- Texto 3: Terror in Paris und die Folgen in Deutschland | DW Nachrichten

—Ámbito político

- Texto 4: Aktuelle Entwicklunge (Bayerisches Staatsministerium des Innern, für Bau und Verkehr. Verfassungsschutzinformationen Bayern I. Halbjahr 2016 - Seite I)

- Texto 5: So emotional reagiert Merkel auf die Terrorserie in Paris

- Texto 6: Jugendspezifische Internetpropaganda und Anwerbeversuche von Salafisten unter Flüchtlingen (Bayerisches Staatsministerium des Innern, für 
Bau und Verkehr. Verfassungsschutzinformationen Bayern I. Halbjahr 2016Seite 7)

—Ámbito legal

- Texto 7: Gesetz über das Bundeskriminalamt und die Zusammenarbeit des Bundes und der Länder in kriminalpolizeilichen Angelegenheiten (Artikel I des Gesetzes über das Bundeskriminalamt und die Zusammenarbeit des Bundes und der Länder in kriminalpolizeilichen Angelegenheiten) (Bundeskriminalamtgesetz - BKAG)

—Ámbito policial

- Texto 8: Terrorismus: Europol: IS plant neue Anschläge in der EU

- Texto 9: Salafismus und Jihadismus

—Ámbito religioso

- Texto 10: Terror - Schuld der Religion?

\section{Análisis con AntConc}

Para llevar a cabo un análisis terminológico de los textos sometidos a estudio, hemos empleado el software libre AntConc. Dicho software está compuesto de herramientas como Concordance, Cluster, Collocates y Wordlist, que permiten al usuario elaborar listados de palabras, agrupamientos léxicos y palabras clave.

En este trabajo mostraremos el ejemplo con un total de diez términos, como muestra significativa del análisis efectuado:

\section{I. Word List}

Una vez importados los 10 textos en lengua origen, la aplicación Word List genera una lista con todas las palabras que aparecen en los archivos del corpus y permite observar las palabras más comunes en estos textos.

- StopWord List: la finalidad de esta aplicación es confeccionar el glosario de palabras especializadas en el contexto que trata, por lo que con la StopWord List podemos eliminar las palabras gramaticales no útiles para nuestro proyecto terminológico (adverbios, artículos definidos e indefinidos, numerales, etc.). 
Obtenemos así un total de cincuenta términos relevantes, en función de la frecuencia de aparición en los textos que conforman el corpus. La imagen siguiente muestra cómo AntConc ofrece al usuario la lista de términos:

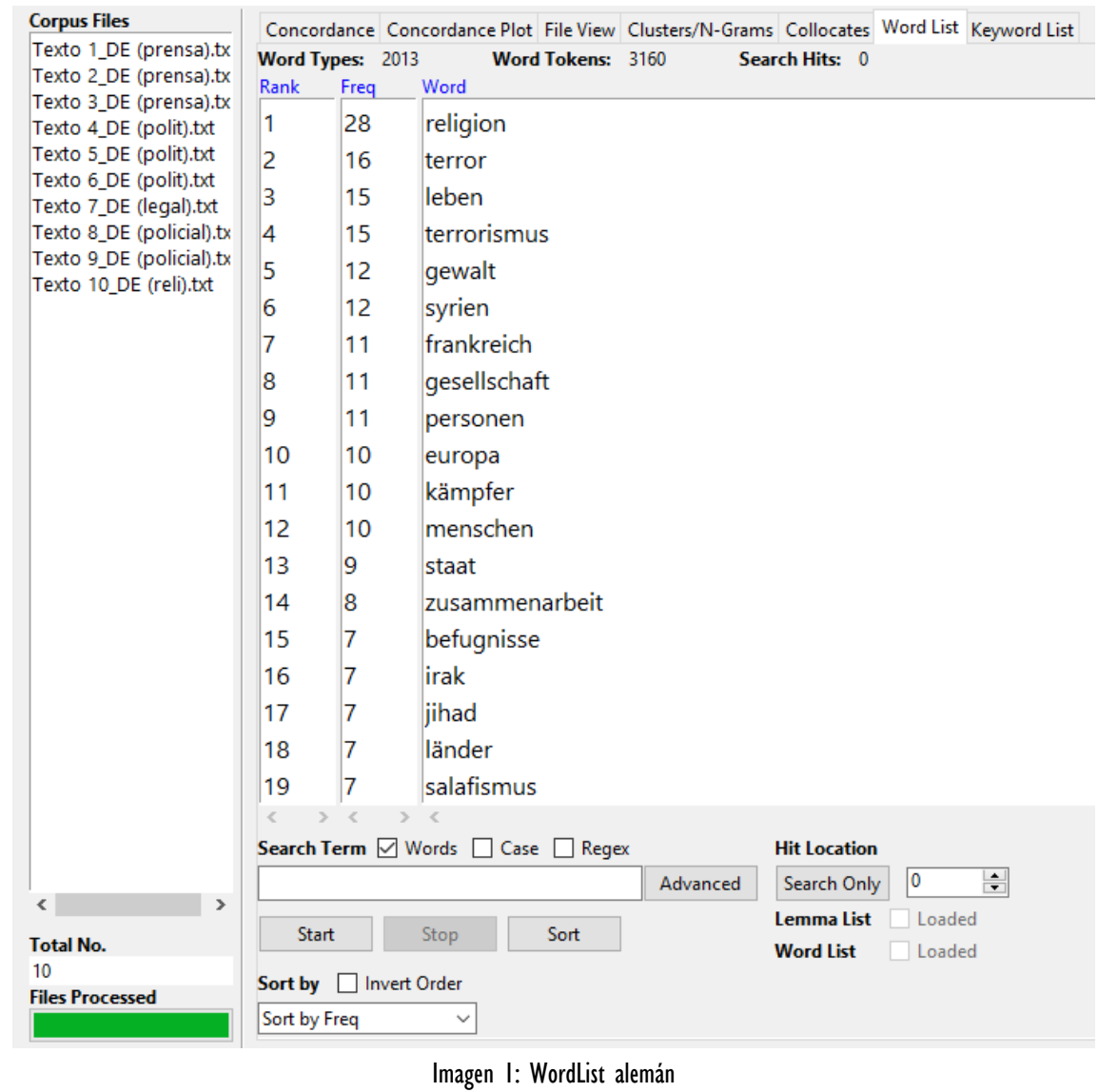

\subsection{Concordance}

Esta herramienta genera concordancias o KWIC (key word in context, es decir, palabra clave en contexto), y sirve para estudiar las colocaciones de los términos. Veamos algunos ejemplos:

a) Concordance I (DE): Gewalt 
Como podemos observar, Gewalt, que significa violencia o fuerza en español, aparece varios textos, empleándose así en numerosas áreas. Recordamos que los textos 4 y 5 pertenecían al ámbito político, mientras que el 9 se engloba en el ámbito policial y el 10 en el religioso. Por tanto, concretamos que la terminología terrorista requiere del término Gewalt como parte fundamental de su lenguaje.

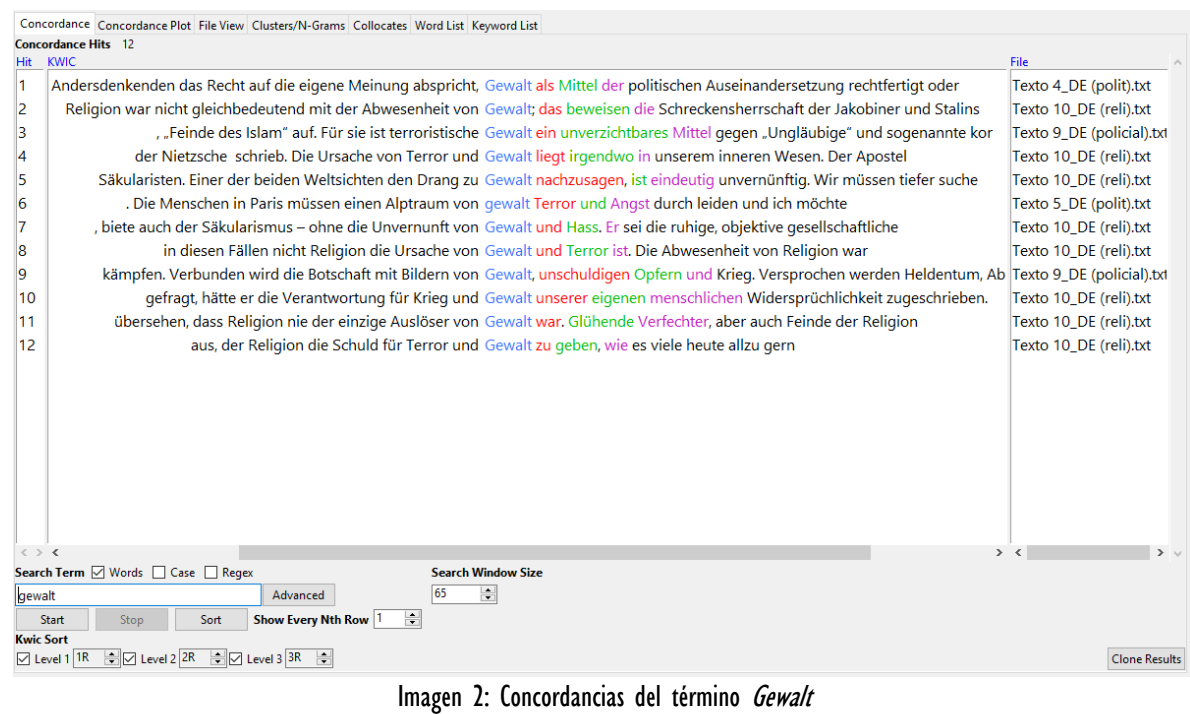

\section{b) Concordance 2 (DE): Terror}

El término Terror es sin duda fundamental en los textos sobre temática terrorista. Aparece tanto en textos periodísticos (textos 2 y 3), como en textos políticos (textos 4 y 5) y religiosos (texto 10). Aparece acompañado de adjetivos o de otros sustantivos que lo enlazan con el terrorismo: Terror-Angriffen (ataques de terror), islamistische Terror (terror islamista), Terror und Angst (terror y temor), Gewalt und Terror (violencia y terror), etc. 


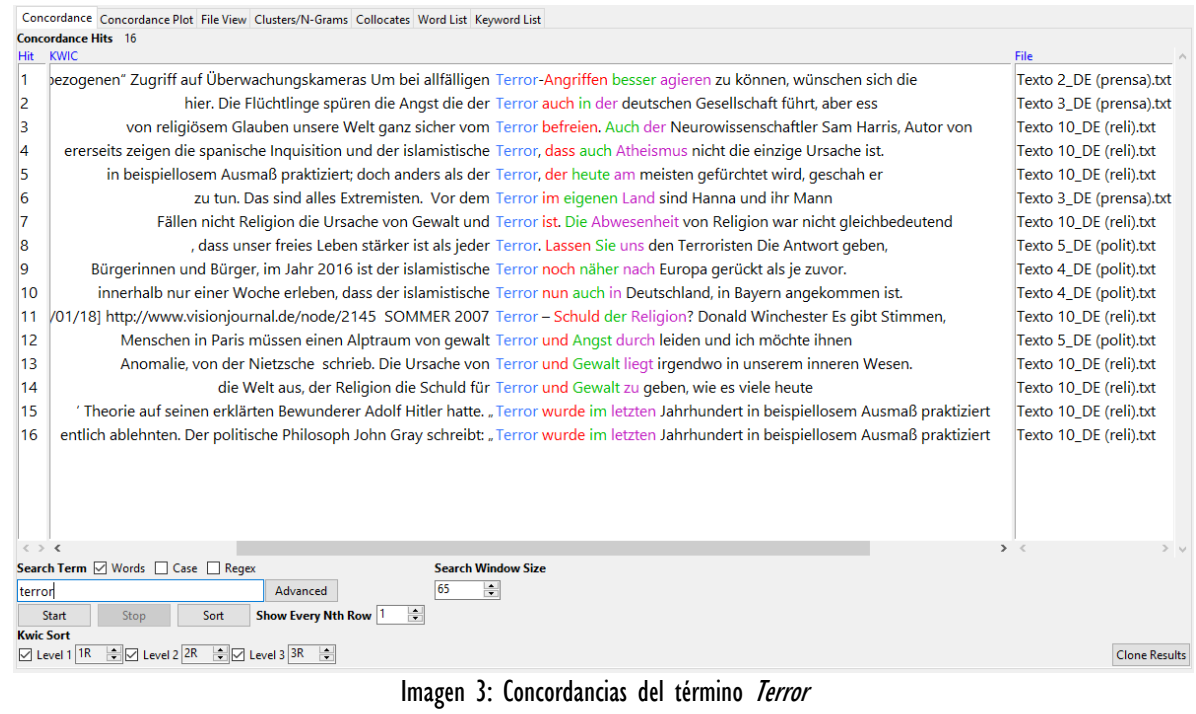

\section{c) Concordance 3 (DE): Religion}

Sin lugar a duda, el término Religion está presente mayoritariamente en el texto 10; no obstante, resulta llamativa su presencia en textos políticos (texto 6) y policíacos (texto 9). De ello, podemos colegir que existe una estrecha relación entre la religión y terrorismo, siendo la primera en numerosas ocasiones el pretexto principal de organizaciones terroristas como Al-Qaeda o ISIS. 


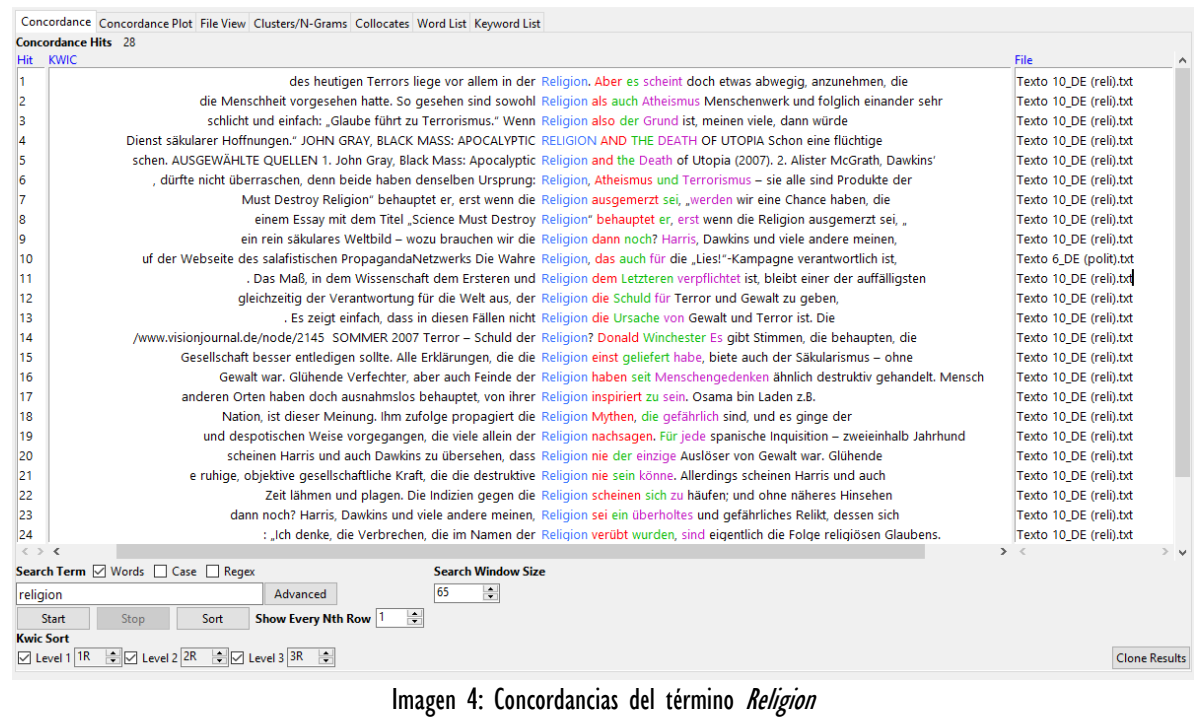

\section{d) Concordance 4 (DE): Kampf}

El término Kampf no es tan frecuente como otros términos, si bien es fundamental en aquellos cuya temática es la lucha antiterrorista. En el corpus aquí analizado aparece en textos periodísticos (texto I), políticos (texto 5), políticos (texto 9) y religiosos (texto 10): 


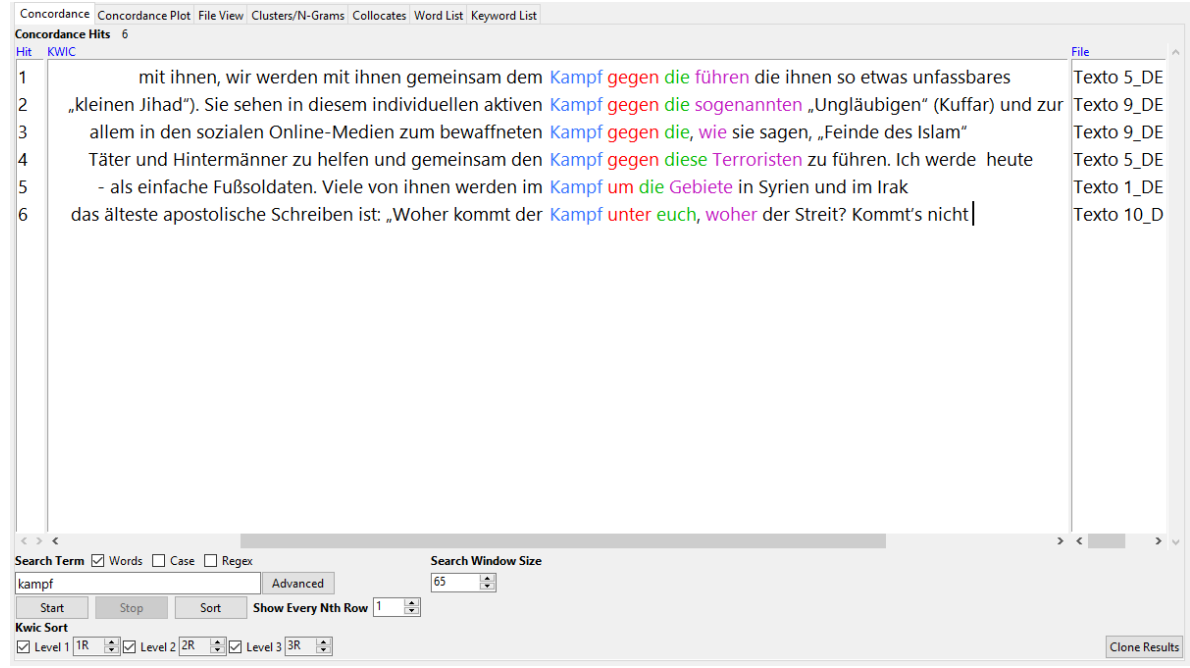

Imagen 5: Concordancias del término Kampf

\section{e) Concordance 5 (DE): Terrorismus}

Terrorismus, junto a religión, es el término más frecuente en los textos. No sorprende su reiterada presencia en prácticamente todos los ámbitos, desde el periodístico (texto 2), hasta el religioso (texto 10), pasando por el político (texto 4), el legal (texto 7) y el policial (texto 8).

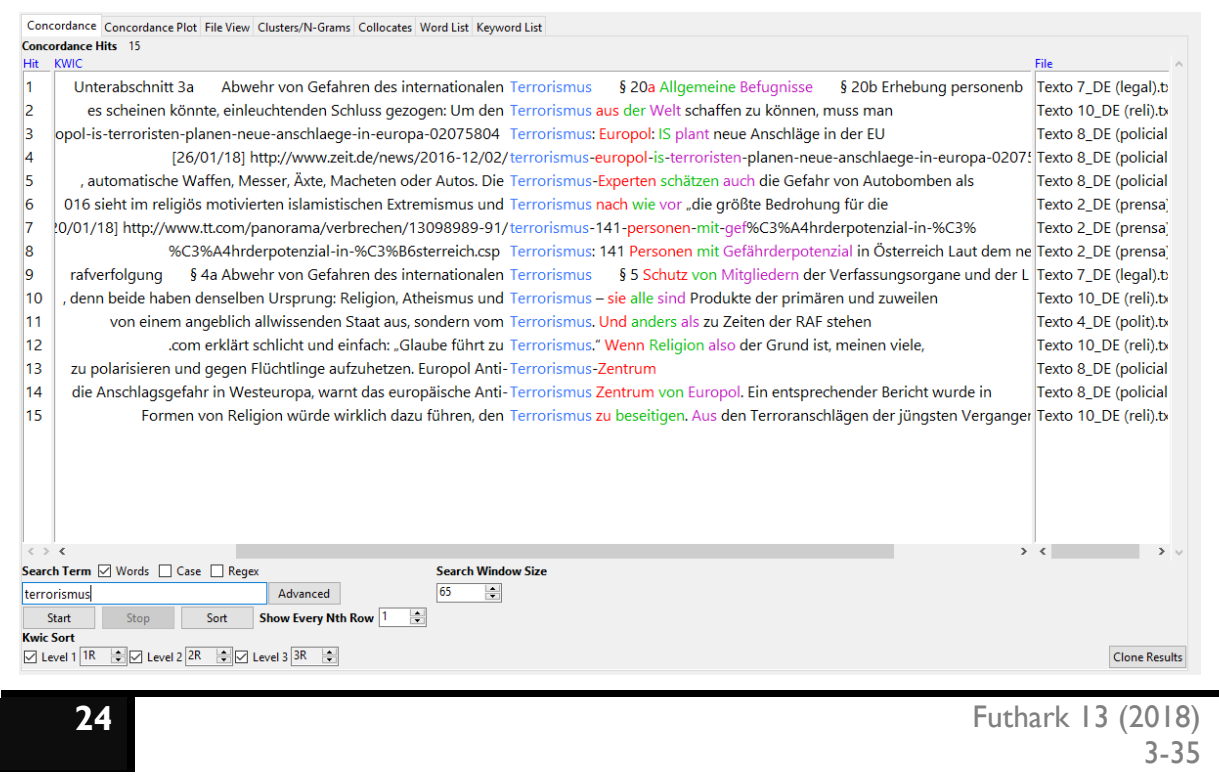




\subsection{Clusters}

Los clusters posibilitan al usuario generar un listado ordenado de agrupaciones de palabras alrededor del término buscado. Gracias a esta aplicación aparecen indicados el número mínimo y máximo de palabras de la agrupación y la orden de aparición del término (de izquierda a derecha de la agrupación). Para comprobar las palabras que rodean los términos sometidos a análisis, recurrimos al orden de aparición del término tanto a la izquierda como a la derecha y con un número mínimo y máximo de 3 palabras en la agrupación.

\section{a) Cluster I (DE): Gewalt}

El término Gewalt aparece como eje central de las construcciones, tanto cuando le rodean por la derecha como por la izquierda. Destacamos algunas construcciones realmente claves en esta materia: Gewalt als Mittel: la violencia como medio/recurso; Gewalt und Hass: violencia y odio; Gewalt und Terror/Terror und Gewalt: violencia y terror/terror y violencia; Alptraum von Gewalt: pesadilla y violencia; Terroristische Gewalt: violencia terrorista; Krieg und Gewalt: guerra y violencia; Ursache von Gewalt: causa de la violencia. 


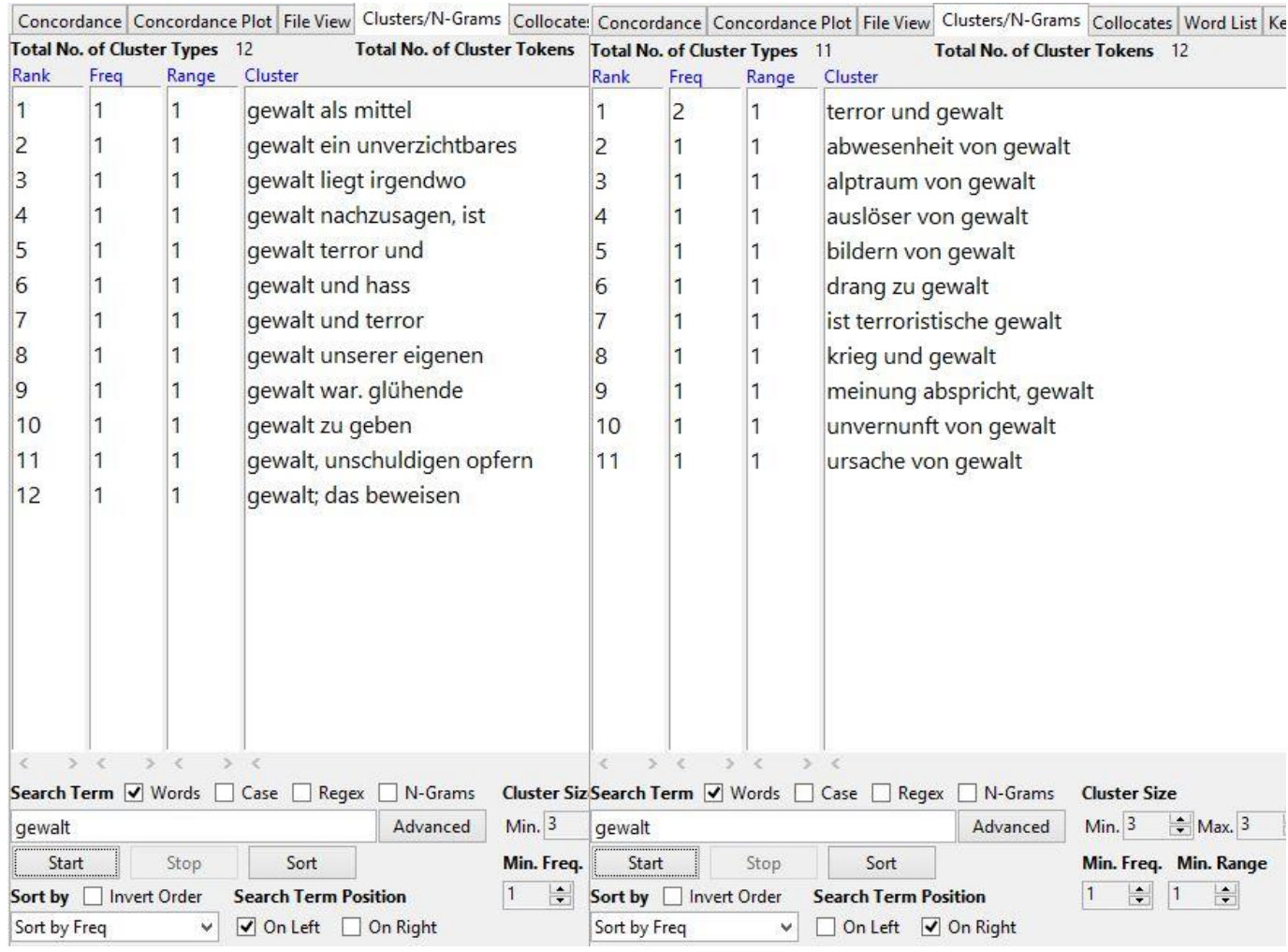

Imagen 7: Clusters del término Gewalt

b) Cluster 2 (DE): Terror

Proponemos una traducción para algunas de las construcciones más frecuentes en estos tipos de textos: Terror und Gewalt: terror y violencia; Terror befreien: liberar(se) (d)el terror; Terror und Angst: terror y miedo; Terror Angriffen: ataques de terror; Islamistischer Terror: terror islamista; Ursache von Terror: motivo del terror. 


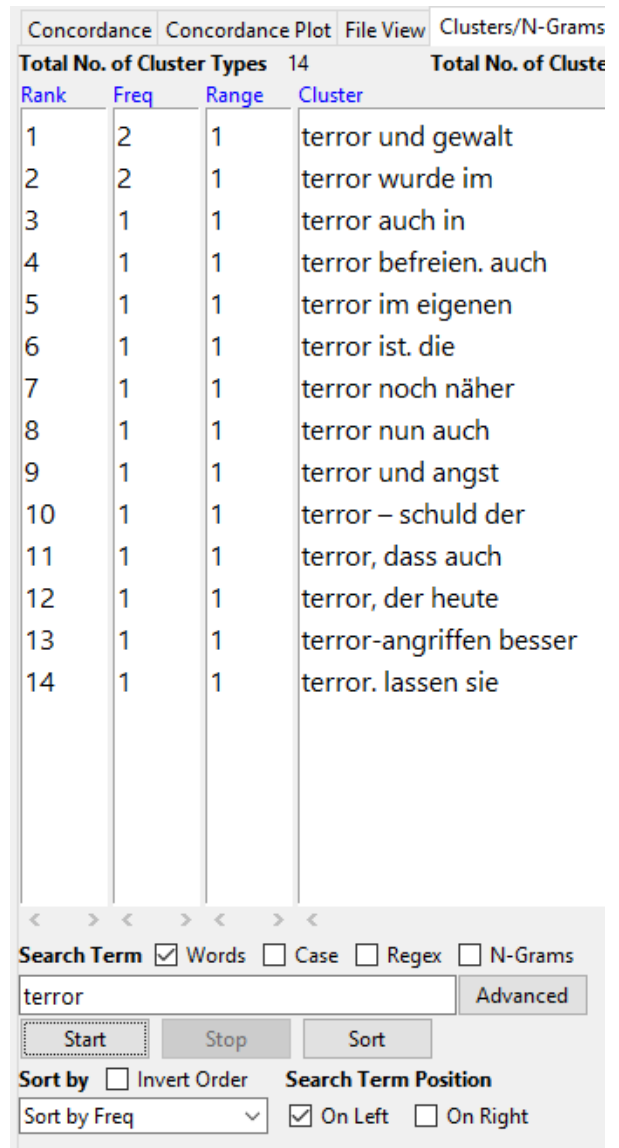

\begin{tabular}{|c|c|c|c|c|c|}
\hline \multicolumn{2}{|c|}{ Concordance } & $\begin{array}{l}\text { ncordanc } \\
\text { er Types }\end{array}$ & $\begin{array}{c}\text { ce Plot File View } \\
14\end{array}$ & Total No. of Cluster Tokens & $\begin{array}{l}\text { Is Collocates } \\
\text { ter Tokens }\end{array}$ \\
\hline Rank & Freq & Range & $\begin{array}{l}14 \\
\text { Cluster }\end{array}$ & & \\
\hline 1 & 3 & 2 & \multicolumn{3}{|c|}{ der islamistische terror } \\
\hline 2 & 1 & 1 & \multicolumn{3}{|c|}{ als der terror } \\
\hline 3 & 1 & 1 & \multicolumn{3}{|c|}{ als jeder terror } \\
\hline 4 & 1 & 1 & \multicolumn{3}{|c|}{ bei allfälligen terror } \\
\hline 5 & 1 & 1 & \multicolumn{3}{|c|}{ die der terror } \\
\hline 6 & 1 & 1 & \multicolumn{3}{|c|}{ gewalt und terror } \\
\hline 7 & 1 & 1 & \multicolumn{3}{|c|}{ gray schreibt: „terror } \\
\hline 8 & 1 & 1 & \multicolumn{3}{|c|}{ hitler hatte. „terror } \\
\hline 9 & 1 & 1 & \multicolumn{3}{|c|}{ node/2145 sommer 2007 terror } \\
\hline 10 & 1 & 1 & \multicolumn{3}{|c|}{ schuld für terror } \\
\hline 11 & 1 & 1 & \multicolumn{3}{|c|}{ sicher vom terror } \\
\hline 12 & 1 & 1 & \multicolumn{3}{|c|}{ ursache von terror } \\
\hline 13 & 1 & 1 & \multicolumn{3}{|c|}{ von gewalt terror } \\
\hline 14 & 1 & 1 & \multicolumn{3}{|c|}{ vor dem terror } \\
\hline$<$ & $<$ & $<\quad$ & $><$ & & \\
\hline \multicolumn{5}{|c|}{ Search Term $\square$ Words $\square$ Case $\square$ Regex $\square$ N-Grams } & Cluster Siz \\
\hline \multicolumn{4}{|c|}{ terror } & Advanced & Min. 3 \\
\hline \multicolumn{2}{|c|}{ Start } & Stop & Sort & & Min. Freq. \\
\hline \multicolumn{3}{|c|}{ Sort by $\square$ Invert Order } & \multicolumn{2}{|c|}{ Search Term Position } & 1 \\
\hline Sort b & Freq & $\checkmark$ & $\square$ On Left $\square$ & On Right & \\
\hline
\end{tabular}

Imagen 8: Clusters del término Terror

c) Cluster 3 (DE): Religion

Los tipos de terrorismo más amenazantes son el político y religioso, y por norma general ambas tipologías suelen tener una estrecha relación. Por ello, el término Religion tiene una gran supremacía en los textos compilados: Religion die Schuld: la religión, la culpable; Religion die Ursache: la religión, el motivo; Religion islamistischer Terroristen: la religión de los terroristas islámicos; Abwesenheit von Religion: ausencia de la religión; Anerkennung ihrer Religion: el reconocimiento de su religión; Die destruktiven Religion: la religión destructiva; Die wahre Religion: la verdadera religión; Feinde und Religion: enemigos y religión; Herkunft oder 
Religion: origen/procedencia y religión; Missbrauch der Religion: abuso de la religión.

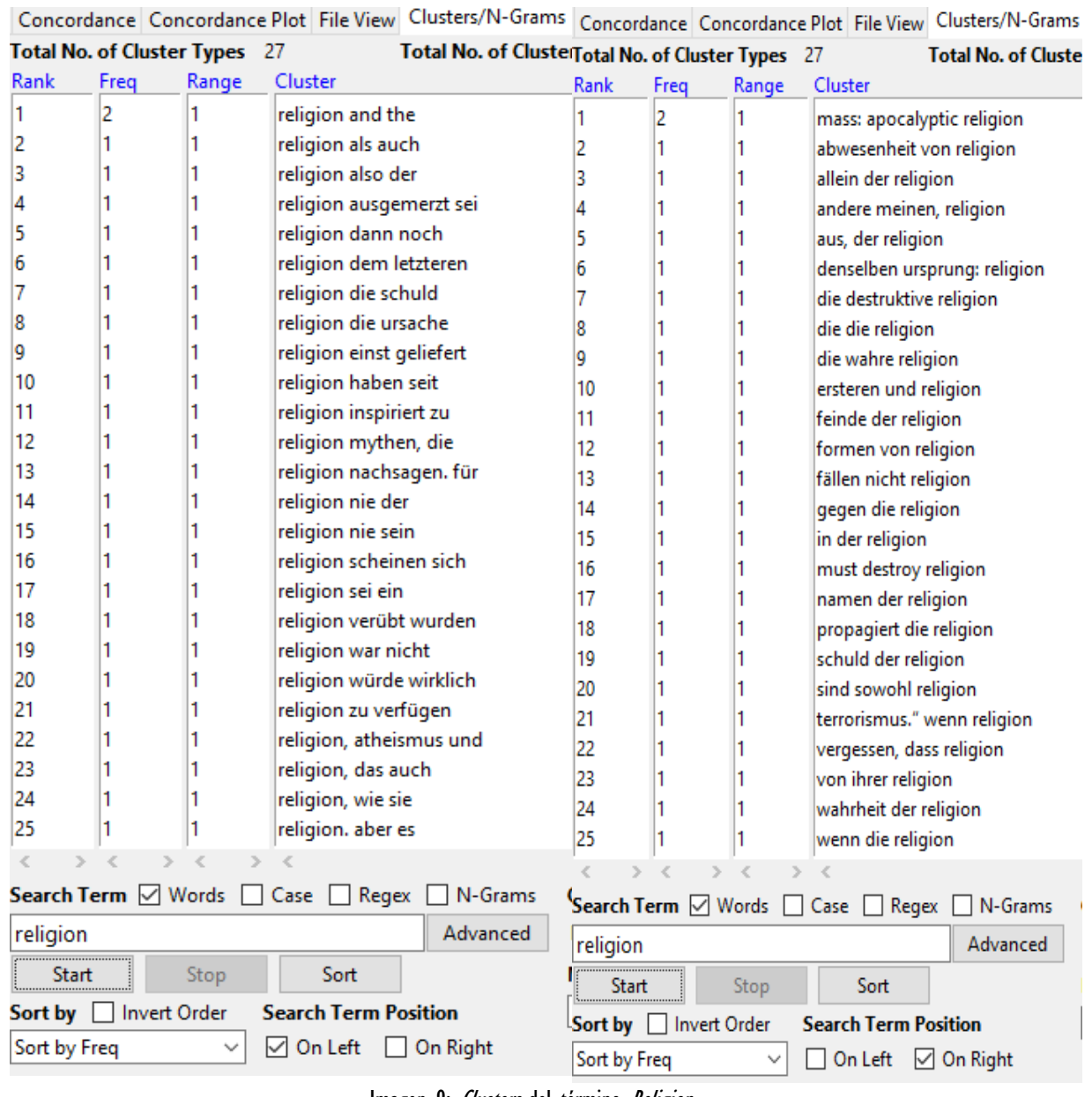

d) Cluster 4 (DE): Kampf

El término Kampf es muy frecuente dentro de la terminología terrorista, bien sea $\circ$ no física, debido a la constante batalla que mantienen los gobiernos contra estas organizaciones y grupos radicales. A continuación, mostramos las construcciones más comunes en alemán con este término y su correspondiente 
propuesta de traducción: Kampf zur Verteidigung: lucha por nuestra defensa; Die bewaffnete Kampf: guerra armada; Gemeinsam den Kampf: juntos en la lucha.

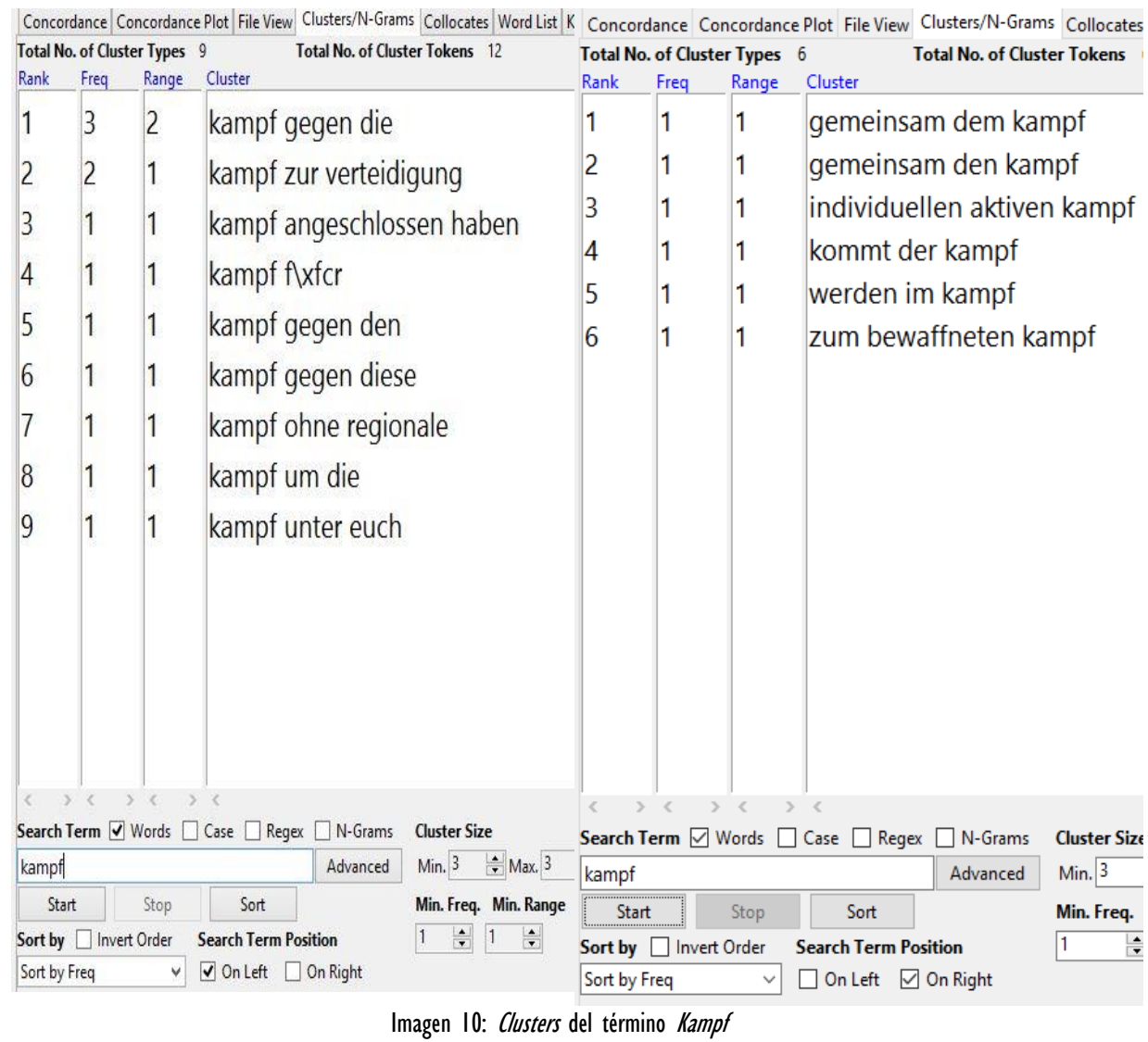

\section{Cluster 5 (DE): Terrorismus}

Indiscutiblemente, el término Terrorismus es el que, con más frecuencia, mayor número de combinaciones presenta. Vemos a continuación algunas de las construcciones más destacadas en los textos alemanes de temática terrorista: Terrorismus durch Muslime: terrorismo por parte de los musulmanes I7; Terrorismus und Ausgrenzung: terrorismo y exclusión; Terrorismus und

\footnotetext{
${ }^{17}$ No es una afirmación, se precisa el contexto para que la construcción tenga sentido.
} 
Terroristiche: terrorismo y terroristas; Terrorismus Experten: expertos en terrorismo; Das internationalen Terrorismus: terrorismo internacional; Atheismus und Terrorismus: ateísmo y terrorismo; Extremismus und Terrorismus: extremismo y terrorismo; Gedankenwelt des Terrorismus: concepto/idea mundial del terrorismo; Jihadismus und Terrorismus: yihadismo y terrorismo; Rechtfertigung des Terrorismus: justificación del terrorismo; Islamistischer Terrorismus: terrorismo islámico.

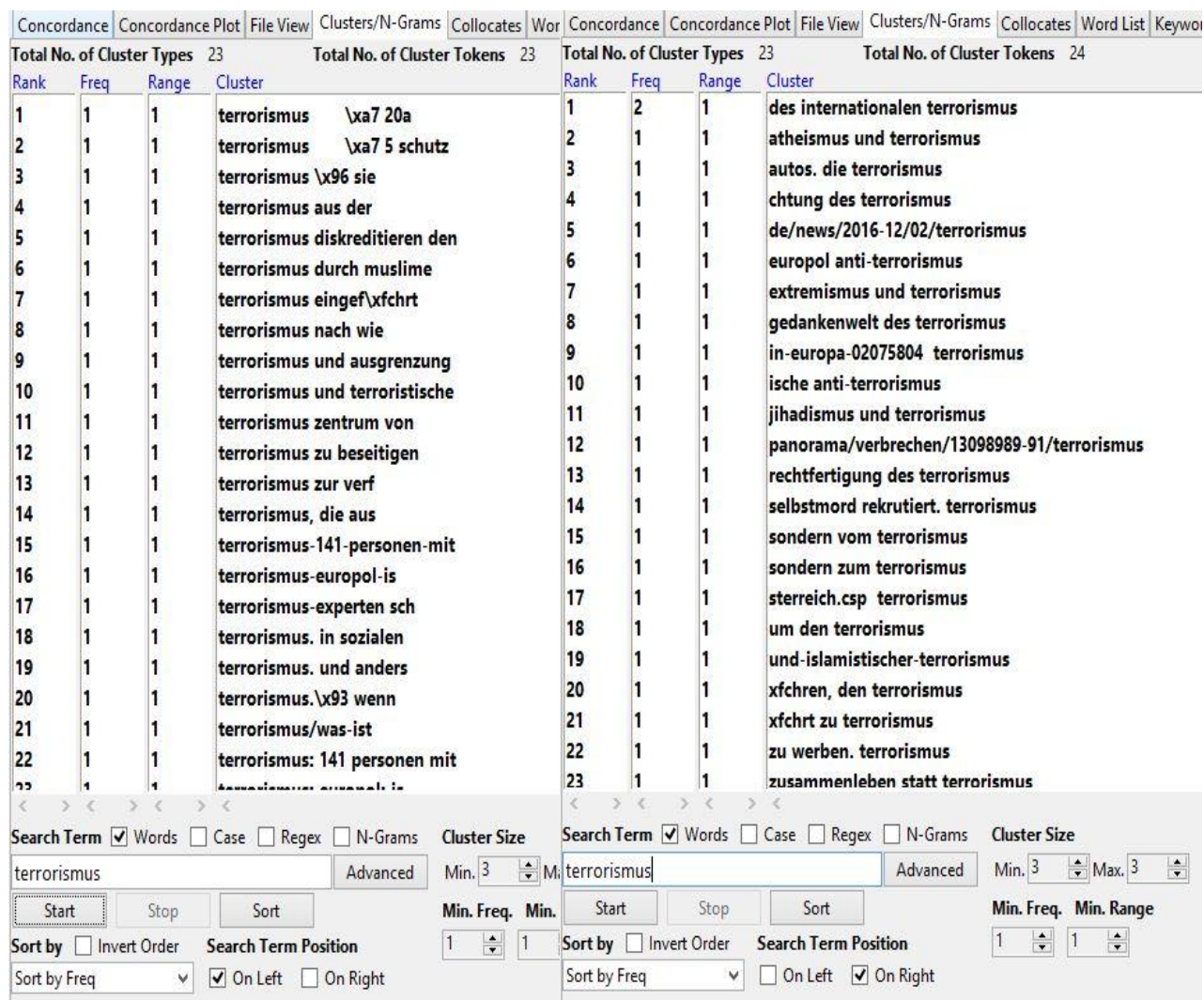

Imagen II: Clusters del término Terrorismus

El estudio llevado a cabo a lo largo de este trabajo nos lleva a las siguientes conclusiones:

I. El análisis practicado en las páginas precedentes posibilita la construcción de una ontología, cuyo hiperónimo es el término [terrorismo], y que puede estar 
relacionada mediante el establecimiento de propiedades o cualidades de los distintos dominios y subdominios léxicos, dando lugar a ontologías satélites como [actores], [tipología], [motivos], [métodos], [antiterrorismo] o [regulación normativa], entre otras.

2. Todos los términos incluidos en cada dominio y subdominio están relacionados, de forma que también lo estarán sus correspondientes equivalencias.

3. Esto permitirá la comunicación fluida entre varios idiomas, con una sistematización del léxico de manera unívoca, lo que redundará en beneficio para traductores e intérpretes, pero también para otros usuarios, como los miembros de los cuerpos de seguridad del Estado.

4. En definitiva, podemos concluir con la relevancia del profesional en Traducción e Interpretación en materia terrorista, actos violentos y depravados que no se producen de forma fortuita, sino que siguen un sistema operativo meditado y elaborado para lograr sus fines. Los grupos terroristas cuentan con apoyo financiero y logístico, en algunos Estados, para divulgar su propaganda, además de un colosal impacto a nivel planetario respaldado por los medios de comunicación.

5. Aquí se halla la labor traductológica, en la cooperación en investigaciones antiterroristas para lograr frenar este monstruo ideológico carente de sensibilidad y sensatez. Para ello, se requiere mayor accesibilidad a documentos oficiales, mayor cooperación policiaca y gubernamental a nivel internacional y mayor financiación en investigaciones de esta índole, tanto a nivel nacional como europeo, para realzar la labor que los profesionales de la Traducción realizan con los cuerpos y fuerzas oficiales del Estado.

\section{Referencias bibliográficas}

Álvarez, L.; Perdomo, C. (2017). Estrategias de ciberseguridad nacional y ciberdefensa en la UE; retos para la estrategia de seguridad y defensa euroclatlántica. En: Durán, M. \& González, R. (coords.). (2017). Los estudios militares y de seguridad en los albores del siglo XXI. Granada: Editorial Universidad de Granada, I89-2I5.

Álvarez, E.; González, H. (2006). Legislación antiterrorista comparada después de los atentados del II de septiembre y su incidencia en el ejercicio de los derechos fundamentales. $\quad$ ARI $7 . \quad\left[\begin{array}{ll}\text { n } \\ \text { línea: }\end{array}\right.$ http://biblioteca.ribei.org/957/I/ARI-7-2006-E.pdf. Fecha de consulta: 2 de marzo de 2018]. 
Bañón, A. M. (2006). La asociación discursiva de terrorismo e inmigración. Un ejemplo de incomunicación intercultural. Revista Internacional de Comunicación Audiovisual, Publicidad y Literatura I (4): 259-277.

Barrenechea, L. (2007). ¿Están recogidas las vinculaciones entre el Derecho de Asilo y el Terrorismo en la Estrategia Global contra el Terrorismo de Naciones Unidas? Revista Electrónica de Estudios Internacionales I4: I- I0. [En línea: http://dialnet.unirioja.es/descarga/articulo/2559807.pdf. Fecha de consulta: 7 de marzo de 2018].

Borja, A. (2008). Corpora for Translators in Spain. En: Anderman, G.; Rogers, M. (eds.). Incorporating Corpora: The Linguist and the Translator. Clevendon: Multilingual Matters, 243-265.

Cañete, P. (2017). El yihadismo como expresión de la violencia, Revista del Instituto Español de Estudios Estratégicos 10, I19-146.

Cantón, J. A. (2017). Cambios en la sociedad europea como consecuencia de la crisis de los refugiados. ¿Amenaza cultural, amenaza terrorista $\circ$ política oportunista? En: Durán, M.; González, R. (coords.). Los estudios militares y de seguridad en los albores del siglo XXI. Granada: Editorial Universidad de Granada, 67-80.

Cobos, I. (2014). Traducción, ciencia y derecho. Skopos. Revista Internacional de Traducción e Interpretación, 4: 49-62.

(20I2). La traducción de sentencias: análisis terminológico y Textual (alemánespañol). Tesis doctoral. Córdoba: Servicio de Publicaciones de la Universidad de Córdoba.

(2009). La traducción jurídica alemán-español: tipos de errores traductológicos. Redit 2: I I-32.

Elorza, A. (2007). Terrorismo y lenguaje. Cuadernos de periodistas: revista de la Asociación de Prensa de Madrid I I: 10-16

Fuentes, X. (2006). Contra la sinonimia y la polisemia en los lenguajes de especialidad. Panace@, Vol. VII, núm. 24: 24I.

Gamero, S. (1999-2000). La traducción de textos técnicos y la diversidad tipológica. Sendebar: Revista de la Facultad de Traducción e Interpretación I0-II: I27152.

García-Abadillo, C. (20I6). El tratamiento periodístico de los atentados. Jornada de terrorismo: medios de comunicación, internet y terrorismo. Madrid: Fundación Manuel Giménez Abad, I-4.

Goig, J. M. (2016). Inmigración, asilo y refugio ante los retos actuales de la política exterior europea. Revista de Derecho UNED I8: 55-84.

González, C. (20I5). La crisis de los refugiados y la respuesta europea. ARI 67. [En línea:

http://consellodacultura.gal/mediateca/extras/texto_GonzalezEnriquez.pdf. Fecha de consulta: 27 febrero 2018]. 
Guild, E. (20I5-20I6). Seguridad, terrorismo y asilo en el espacio Schengen. Anuario CIDOB de la Inmigración, 58-78.

Hoffmann, L. (1998). Llenguatges d'especialitat. Selecció de textos. Barcelona: IULAUPF.

Ibarra, E. (20I5). Crisis de los refugiados, terrorismo y auge de la islamofobia. Apuntes para el debate. Cuadernos de análisis 56: 5-2I.

Jackson, R. (2016). Repensando el "terrorismo" desde lo internacional. Relaciones Internacionales, Grupo de Estudios de Relaciones Internacionales (GERI) 32: I I14.

(20I3). The Politics of Terrorism Fear. En: Sinclair, S. J. (ed.), The Political Psychology of Terrorism Fears. Cambridge: Cambridge University Press, 267282.

Jordán, J. (2009). Políticas de prevención de la radicalización violenta en Europa: elementos de interés para España. Revista electrónica de Ciencia Penal y Criminología II (5). [En línea: http://criminet.ugr.es/recpc. Fecha de consulta: 29 abril 2018].

(20I4). The evolution of the structure of jihadist terrorism in Western Europe: the case of Spain. Studies in Conflict and Terrorism 37 (8): 654-673.

Kaldor, M. (2003). Terrorismo global. Papeles 84: II-29.

Knight, K. (2017). Prácticas de exclusión de refugiados en Estados Unidos. Migraciones Forzadas 54, 52-53.

Llorente, J. (2016). Sobre el miedo, el terrorismo, los refugiados, tú y yo. En la calle: revista sobre situaciones de riesgo social, I-4.

Lluis, M. (2016). La prensa y el terrorismo. Jornada de terrorismo: medios de comunicación, internet y terrorismo. Madrid: Fundación Manuel Giménez Abad, I-9.

Lobato, P. (2017). ¿Existe un perfil del terrorista jihadista?. En: Durán, M.; González, R. (coords.), Los estudios militares y de seguridad en los albores del siglo XXI. Granada: Editorial Universidad de Granada, I49-163.

López, N. (2002). El concepto de terrorismo. ¿Qué terrorismo? ¿Por qué el terrorismo? ¿Hasta cuándo el terrorismo? Anuario de filosofía del derecho 19: $51-7 \mid$.

Marica, A. (2017). Medidas y cambios en la Unión Europea para intensificar la lucha contra el terrorismo global. Revista del Instituto Español de Estudios Estratégicos 10: 13-54.

Martín Corrales, C. (2007). Terrorismo nuclear. Boletín de Información (Ministerio de Defensa), 17-40.

Milosevich, M. (2006). El islam europeo: entre la integración y la radicalización. Cuadernos de pensamiento político, 209-219.

Morán, M. T. (eds.) (2002). Texto, terminología y traducción. Salamanca, Ediciones Almar, 15-36. 
Nord, Ch. (1996). El error en la traducción: categorías y evaluación. En: Studis sobre la traducció, 91-107.

Osorio y Florit, M. (2006). Diccionario de Ciencias Jurídicas, Políticas y Sociales. Buenos Aires, Heliasta.

Pegenaute, L. (20I2). La traducción como herramienta preventiva y paliativa del terrorismo internacional. En Rabadán, R.; Guzmán, T.; Fernández, M. (eds.), Lengua, traducción, recepción: en honor de Julio César Santoyo. León: Universidad de León, 395-408.

Powell, C.; Somoza, A. (2009). La Unión Europea y la lucha contra el terrorismo global. Política Exterior 23 (I27): I27-I37.

Reinares, F. (29 de enero de 2008). 'Yihadismo' paquistaní en Barcelona. El País. Recuperado de: https://elpais.com/diario/2008/0I/29/opinion/I20I56I2I3_8502I5.html (2004). Del terrorismo internacional al terrorismo global. Letras libres 31 : 28-3I.

Revilla, P (2005). El terrorismo global. Inicio, desafíos y medios político-jurídicos de enfrentamiento. Anuario Mexicano de Derecho Internacional 5. [En línea: https://revistas.juridicas.unam.mx/index.php/derechointernacional/article/view/I25/I90. Fecha de consulta: 7 de mayo 20I8].

Rodríguez, J. M.; Ceballos, P.; Álvarez, P.; Rey, P. (2017). Radicalización islamita: un análisis conceptual. En: Durán, M.; González, R. (coords.), Los estudios militares y de seguridad en los albores del siglo XXI. Granada: Editorial Universidad de Granada, 29-43.

Rodríguez-Perdomo, T. (20I2). La polisemia en la traducción jurídico-médica. En: Panace@, Vol. XIII (36): 32I-326.

Zanettin, F. (1998). Bilingual Comparable Corpora and the Training of Translators. Meta 43 (4): 616-630.

Torres, M.; Jordán, J. (2013). Terrorismo. En: Jordán, J. (coord.), Manual de estudios estratégicos y seguridad nacional. Madrid: Plaza y Valdés, 307-328.

Savater, F. (2004). La lucha contra el terrorismo. Archivos del presente. Revista latinoamericana de temas internacionales 9: 23-39.

- Recursos disponibles en la red

Consejo de la Unión Europea: http://www.consilium.europa.eu/es/

Diccionario en línea PONS: http://es.pons.com/

Diccionario en línea WORDREFERENCE: http://www.wordreference.com/

IATE - The EU's multilingual term base. Recurso disponible en la red: http://iate.europa.eu

INTERPOL: https://www.interpol.int/es/Internet 
LA

MONCLOA

Gobierno

de

España:

http://www.lamoncloa.gob.es/serviciosdeprensa/notasprensa/maec/Paginas/ 2014/2609/4resolucionnacionesu.aspx

LIBRARY OF CONGRESS: http://www.loc.gov/law/help/foreign-fighters/eu.php

Ministerio de Defensa - IEEE, Terrorismo Internacional. Enfoques y percepciones, (2005), [En línea: file:///C:/Users/carmeli2014/Downloads/DialnetTerrorismolnternacional-562679\%20(I).pdf. Fecha de consulta: 30 abril 2018].

REAL ACADEMIA ESPAÑOLA, Diccionario de la lengua española [en línea]. Recurso disponible en: http://www.rae.es/

REUTERS: https://www.reuters.com/

SISTEMA DE SEGURIDAD NACIONAL, Gobierno de España: http://www.dsn.gob.es/es/actualidad/sala-prensa/nueva-directiva-contraterrorismo

UNITED NATIONS: http://www.un.org/en/index.html

USA GOV: https://www.congress.gov/

一Jurisprudencia

Boletín Informativo de la Unión Europea: https://publications.europa.eu/es/newsletter

Boletín Oficial del Estado: https://www.boe.es/

EUR-Lex: El acceso al Derecho de la Unión Europea: https://eurlex.europa.eu/homepage.html?locale=es

Juris: https://www.gesetze-im-internet.de/

Noticias Jurídicas: http://noticias.juridicas.com/

United Nations Legislative Series: http://legal.un.org/legislativeseries/ 
